\title{
Chemical Defense in Elodea nuttallii Reduces Feeding and Growth of Aquatic Herbivorous Lepidoptera
}

\author{
Daniela Erhard • Georg Pohnert • Elisabeth M. Gross
}

\begin{abstract}
The submersed macrophyte Elodea nuttallii (Hydrocharitaceae) is invasive in Europe and frequently found in aquatic plant communities. Many invertebrate herbivores, such as larvae of the generalist aquatic moth, Acentria ephemerella (Lepidoptera, Pyralidae), avoid feeding on E. nuttallii and preferably consume native species. First instar larvae exhibited a high mortality on E. nuttallii compared to the native macrophyte Potamogeton perfoliatus. Mortality of older larvae was also high when fed E. nuttallii exposed to high light intensities. Growth of older larvae was strongly reduced on E. nuttallii compared to pondweeds (Potamogeton lucens). Neither differences in nitrogen nor phosphorus content explained the different performance on these submerged macrophytes, but plants differed in their flavonoid content. To investigate whether plant-derived allelochemicals from E. nuttallii affect larval performance in the same way as live plants, we developed a functional bioassay, in which Acentria larvae were reared on artificial diets. We offered larvae Potamogeton leaf disks coated with crude Elodea extracts and partially purified flavonoids. Elodea extracts deterred larvae from feeding on otherwise preferred Potamogeton leaves, and yet, unknown compounds in the extracts reduced growth and survival of Acentria. The flavonoid fraction containing luteolin-7-O-diglucuronide, apigenin-7- $O$-diglucuronide, and chrysoeriol-7- $O$-diglucuronide strongly reduced feeding of larvae, but did not increase mortality. The concentrations of these compounds in our assays were $0.01-0.09 \%$ of plant dry mass, which is in the lower range of
\end{abstract}

D. Erhard $(\bowtie) \cdot$ E. M. Gross

Limnological Institute, University of Konstanz, Box M 659, D-78457 Konstanz, Germany

e-mail: daniela.erhard@wzw.tum.de

E. M. Gross

e-mail: Elisabeth.Gross@uni-konstanz.de

G. Pohnert

Institute for Inorganic and Analytical Chemistry, Bioorganic Analytics, Friedrich-Schiller-University, Lessingstr. 8, D-07743 Jena, Germany

e-mail: Georg.Pohnert@uni-jena.de

Present address:

D. Erhard

Limnological Station, TU Munich, Hofmark 3, D-82393 Iffeldorf, Germany

Konstanzer Online-Publikations-System (KOPS)

URL: http://www.ub.uni-konstanz.de/kops/volltexte/2008/5012/

URN: http://nbn-resolving.de/urn:nbn:de:bsz:352-opus-50128 
concentrations found in the field (0.02-1.2\%). Chemical defense in E. nuttallii thus plays an ecologically relevant role in this aquatic plant-herbivore system.

Keywords Allelochemicals · Feeding deterrence - Freshwater macrophyte - Herbivory · Invasive plant $\cdot$ Nutritional value $\cdot$ Flavonoids

\section{Introduction}

The North American waterweeds Elodea canadensis and Elodea nuttallii are invasive submersed macrophytes in Europe. E. nuttallii Planch. St. John, in particular, is still spreading over Europe and is found in many waterbodies. Waterweeds are competitive, well adapted to a broad array of environmental conditions (Cook and Urmi-König 1985; Simpson 1990), and contain allelochemicals that are active against competing algae and cyanobacteria (Erhard and Gross 2006).

Although Elodea species are often preferred food for waterfowl or crayfish (Lodge 1991; van Donk and Otte 1996), they are avoided by many insect herbivores (Newman 1991 and references therein). E. nuttallii is avoided by herbivorous larvae of Acentria ephemerella (Pyralidae, Lepidoptera, Denis and Schiffermüller), which cause severe damage to other freshwater macrophytes, such as Potamogeton spp. or Myriophyllum spicatum L. (Gross et al. 2002). Although Berg (1941) reported feeding of Acentria larvae on E. canadensis in Danish lakes, a study performed at the Finger Lakes, USA, showed that Acentria avoided E. canadensis when M. spicatum was available, and larvae had a higher mortality on the former (Gross et al. 2001). Avoidance of potential host plants and bad performance is often related to low food quality, i.e., poor nutritional quality, the presence of chemical deterrents or toxins.

In general, nitrogen content is considered the major nutrient determining food quality of plants, and many Lepidoptera prefer plants with the highest nitrogen content (White 1993; Newman et al. 1996). Phosphorus may also limit the growth of Lepidoptera larvae (Perkins et al. 2004). Yet, both E. canadensis and E. nuttallii have high nitrogen and phosphorus contents (Boyd 1968; Jewell 1971; Newman 1991; Kornijow et al. 1995).

While chemical deterrents are well-known to influence host plant selection and performance of herbivores in terrestrial systems, little is known about similar relationships between freshwater plants and their herbivores. Several aquatic angiosperms contain alkaloids (Ostrofsky and Zettler 1986), and watercress tissue is protected by glucosinolates (Newman et al. 1996), both groups of secondary metabolites known as potent feeding deterrents in terrestrial plants. Hydrolyzable polyphenols present in M. spicatum possibly affect the growth of Acentria larvae (Choi et al. 2002; Walenciak et al. 2002), but larvae still develop into pupae and adults. Some flavonoids seem to deter aquatic herbivores, e.g., deoxyanthocyanin from the aquatic fern Azolla pinnata (Cohen et al. 2002). Elodea species contain flavone glucosides (Mues 1983), which might act as feeding deterrents, although they were inactive in allelopathic interactions (Erhard and Gross 2006).

The investigation of chemical defenses against herbivores requires the use of artificial diets (Hay et al. 1998). Filter disks and artificial diets supplemented with pure chemicals or plant extracts have been extensively used to feed terrestrial caterpillars such as Lymantria, Spodoptera, or Helicoverpa (Beninger and Abou-Zaid 1997; Calderon et al. 2001; Simmonds and Stevenson 2001). Diets based on agar have been successfully fed to marine omnivores like amphipods, isopods, or sea urchins (Hay et al. 1994; Cruz-Rivera and Hay 2003). So far, only a few studies have addressed feeding deterrents in submersed freshwater plants, and studies with herbivorous freshwater insects are especially rare (see Dorn et al. 
2001). Mostly crayfish have been used in bioassays, as these omnivores feed in a wide variety of laboratory assays (Lodge 1991; Bolser et al. 1998; Kubanek et al. 2001). Thus far, nobody has succeeded in rearing Acentria or other aquatic lepidoptera on food other than submersed macrophytes. The larvae avoid all common artificial diets (Choi et al. 2002) that would allow adding antifeedants to their food.

Here, we investigated the performance of neonate and older larvae of Acentria ephemerella reared on E. nuttallii or pondweeds. We determined content of nutrients and flavonoids in pondweeds and in E. nuttallii grown under both high or low light to investigate which factor(s) affect this generalist moth larvae. We also developed a bioassay to test the effect of potential allelochemicals, especially flavonoids, on Acentria.

\section{Methods and Materials}

Plants E. nuttallii was collected in summer or autumn in Lower Lake Constance at the Island of Reichenau and also from a small pond at the campus of the University of Konstanz, Germany. Plants were transported to the laboratory on ice and rinsed with tap water to remove algae and debris. They were shock-frozen in liquid nitrogen and stored at $-20^{\circ} \mathrm{C}$ until lyophilization. Potamogeton perfoliatus came from Lower, and Potamogeton lucens from Upper Lake Constance. The latter was cultivated in aquaria at $16^{\circ} \mathrm{C}, 30-70 \mu \mathrm{mol} \mathrm{m} \mathrm{sec}^{-1}$ and at a light cycle of L:D 16:8 hr. Leaves of $P$. lucens were harvested immediately before use in feeding assays.

Larvae Diapausing larvae of Acentria aged third to fifth instar were collected in autumn 2003 in Lower Lake Constance. Stems of P. perfoliatus containing the overwintering larvae were placed into 1.5-1 glass jars with dechlorinated tap water and kept at $4{ }^{\circ} \mathrm{C}$ in a cooling chamber in the dark. Larvae left their hibernicula after 3-5 mo and were then used in bioassays.

Analysis of Plant Nutrient Content Carbon and nitrogen were measured with an elementar analyzer NCS 2500 (CE Instruments/Thermoquest) with atropine sulfate as a standard (58.8\% C, 4.0\% N, C:N molar ratio 17:1). Phosphorus was determined with an N/P autoanalyzer after acidic persulfate digestion. Due to low biomass, not all plant samples were available for nutrient analysis, resulting in $N=2-10$.

Analysis of Plant Chemistry Lyophilized and finely ground plants of E. nuttallii were extracted twice in 50\% $(v / v)$ aqueous methanol [1 ml solvent per $10 \mathrm{mg}$ plant dry mass (dm)] for $2 \mathrm{hr}$ each. After evaporation of methanol, the concentrated extract was split into two aliquots. One aliquot was further evaporated to dryness and resuspended in ultrapure water (final concentration $100 \mathrm{mg}$ plant $\mathrm{dm} \mathrm{ml}^{-1}$ ), yielding the crude polar extract that was used in larval bioassays. The second aliquot was adjusted to $2.5 \%$ aqueous methanol $(v / v)$ and fractionated by solid phase extraction (SPE) on a C18 cartridge (2 g sorbens, Phenomenex). After washing with $2.5 \%$ methanol, the C18 cartridge was stepwise eluted with $10-100 \%$ methanol at $10 \%$ intervals, yielding 11 fractions, including the wash fraction. Fractions were evaporated to dryness and resuspended in water (fractions 1-6 that eluted with $10-50 \%$ methanol) or $50 \%$ methanol (fractions $7-11$, eluted with $60-100 \%$ methanol). HPLC analysis with a reversed phase $\mathrm{C} 18 \mathrm{LiChrospher} \mathrm{column}(250 \times 4 \mathrm{~mm})$, a linear gradient with $1 \%$ aqueous acetic acid and methanol as solvents, and a photodiode array detector set at $345 \mathrm{~nm}$ as primary detection wavelength (details in Erhard and Gross, 2005) showed that 
fraction 2 (eluted with 10\% methanol) contained flavonoids. This fraction was used in feeding assays. Control extracts and fractionations were performed accordingly, using only solvents but no plant material. Concentrations of luteolin-7-O-diglucuronide were calculated from a calibration curve [regression equation: luteolin-7-O-diglucuronid $(\mu \mathrm{g})=$ peak area at $345 \mathrm{~nm}$

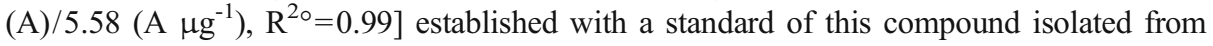
Elodea. As no pure standards of the glucuronids of apigenin and chrysoeriol were available, we quantified those by their peak areas assuming similar extinction coefficients as for the luteolin-diglucuronide.

Purified metabolites were obtained by extracting $15.5 \mathrm{~g}$ fresh E. nuttallii, which was homogenized in $250 \mathrm{ml}$ of $50 \%$ methanol by using a blender and vigorously stirred over night. After filtration under reduced pressure, the resulting pellet was again treated with $250 \mathrm{ml}$ of $50 \%$ methanol and stirred for $2 \mathrm{hr}$. The solvent was removed under reduced pressure, and the remaining residue taken up in $5 \mathrm{ml}$ of $50 \%$ methanol. After centrifugation, the crude polar extract was separated by repeated injections on a preparative HPLC (Gilson $321)$ using a GromSil 120 ODS-4 column $(250 \times 4 \mathrm{~mm})$. Separation of the flavonoids was achieved with a linear gradient of $0.5 \%$ aqueous formic acid and methanol starting from $25 \%$ methanol to $75 \%$ methanol over $30 \mathrm{~min}$. The compounds were identified by two-dimensional NMR techniques and by comparison of the ${ }^{13} \mathrm{C}$ NMR data with the literature (Mues 1983).

Preparation of E. nuttallii-Supplemented Leaves We supplemented P. lucens leaf squares with crude polar extract or isolated flavonoids from $E$. nuttallii. Leaves from $P$. lucens were dissected in small pieces of approximately $4 \times 4 \mathrm{~mm}$, omitting the midrib. Leaf squares were placed in 24-well tissue culture plates (two pieces per well) and incubated for $24 \mathrm{hr}$ in aqueous extract, the aqueous flavonoid fraction (100 mg plant $\mathrm{dm} \mathrm{ml}^{-1}$ each), or the respective controls (400 $\mu 1$ per well). These impregnated leaf squares were used in feeding assays.

The success of leaf supplementation was verified by extracting flavonoids from incubated leaf squares not fed to larvae. Leaf squares were frozen in liquid nitrogen directly after incubation in crude polar extract $(0 \mathrm{hr})$ and $24 \mathrm{hr}$ after application to the inner filter (see below). They were freeze-dried, weighed, and extracted twice for $2 \mathrm{hr}$ with $500 \mu \mathrm{l} 50 \%$ methanol in a sonication bath. Aliquots of the extracts were analyzed by HPLC, and we determined the concentration of luteolin-7- $O$-diglucuronide per milligram dry $P$. lucens leaf square to evaluate the effectiveness of supplementation.

\section{Feeding Assays}

Performance of First Instar Larvae (Experiment I) In summer 2002, we successfully reared in the laboratory adults that oviposited on P. perfoliatus in aquaria. Egg clutches were separated, and neonate larvae hatching from a distinct clutch were divided into four groups, each receiving different diets. The first group was fed E. nuttallii (EN) from the campus pond, while two other groups were fed for 3 (PF1) or 5 wk (PF2) P. perfoliatus, before receiving $E$. nuttallii. The last group (PF3) got exclusively $P$. perfoliatus $(N=17-34$ per group, for details see Table 1). Larvae were raised in 24-well microtiter plates filled with $2 \mathrm{ml}$ dechlorinated tap water. Larvae received fresh food and water biweekly, and growth was measured by their head capsule width after 3, 5, and 7 wk.

Performance of Older Larvae (Experiments II and III) We performed four no-choice feeding assays, two using E. nuttallii shoot fragments or P. lucens leaves ("fresh plants", experiments IIa and IIb) and two using supplemented leaves (experiments IIIa and IIIb). 
Table 1 Numbers of surviving and dead Acentria larvae in the different treatments of experiment I after $7 \mathrm{wk}$

\begin{tabular}{llllll}
\hline Treatment & & Number $(N)$ & Survivors & Dead \\
\hline Clutch I & EN & 18 & 0 & 18 & $\mathrm{a}$ \\
& PF1 & 17 & 3 & 14 & $\mathrm{a}, \mathrm{b}$ \\
& PF2 & 17 & 5 & 12 & $\mathrm{~b}$ \\
\multirow{3}{*}{ Clutch II } & PF3 & 17 & 6 & 11 & $\mathrm{~b}$ \\
& EN & 34 & 3 & 31 & $\mathrm{a}$ \\
& PF1 & 34 & 2 & 32 & $\mathrm{a}$ \\
& PF2 & 33 & 11 & 22 & $\mathrm{~b}$ \\
& PF3 & 33 & 11 & 22 & $\mathrm{~b}$ \\
\hline
\end{tabular}

Different letters indicate significant differences at the end of the experiments $\left(\chi^{2}\right.$-tests, $\left.P<0.05\right)$.

$P F 1$ Reared on $P$. perfoliatus for 3 wk, then fed $E$. nuttallii, $P F 2$ reared on $P$. perfoliatus for 5 wk, then fed $E$. nuttallii, PF3 fed P. perfoliatus only, EN: fed E. nuttallii only

Before all assays, larvae were kept individually in 50-mm glass petri dishes filled with $8 \mathrm{ml}$ of dechlorinated tap water. They were reared on P. lucens for $1 \mathrm{~d}$ at $16^{\circ} \mathrm{C}$ in dim light $\left(30 \mu \mathrm{mol} \mathrm{m} \mathrm{m}^{-2} \mathrm{~s}^{-1}, 16: 8 \mathrm{~L}: \mathrm{D}\right)$ to make sure that all individuals were actively feeding. After measuring their headcapsule width, larvae were equally distributed to the different treatments $(N=13-15$ per treatment) to avoid uneven initial headcapsule widths between treatments. Each larva was transferred to a new petri dish filled either with tap water (experiment II) or covered with moist filter paper (Macherey \& Nagel, MN615) at the bottom (experiment III). In the latter case, we used two filters: a ring, cut from a 55-mm diameter filter, covered the rim of the bottom, whereas a $27-\mathrm{mm}$ diameter filter was placed in the middle of the petri dish to carry the leaf disk.

As light intensity might influence nutrient composition and content of potential allelochemicals, we tested in two independent experiments whether Acentria responds differently to Elodea grown under high or low light. Control larvae received $P$. lucens. In experiment IIa ( $N=13$ per treatment), Elodea plants were collected from two different sites of the university pond. One site was exposed to full sunlight, whereas the other was in the shade and seldom received full sunlight. Midday light intensities varied between 780 and $1,490 \mu \mathrm{mol} \mathrm{m}{ }^{-2} \mathrm{~s}^{-1}$ at the sun-exposed site and 107-382 $\mu \mathrm{mol} \mathrm{m} \mathrm{m}^{-2} \mathrm{~s}^{-1}$ at the shaded site (measured directly under the water surface on five summer days). Water temperature was, in general, $16-18^{\circ} \mathrm{C}$, but reached up to $21^{\circ} \mathrm{C}$ in sun-exposed areas.

Experiment IIb was conducted to determine if light intensity and not other site factors affected eventual differences in plant chemistry or nutrients. We established cultures of pond E. nuttallii under controlled conditions in a light chamber. One or two cleaned shoots each were planted in 16 1.5-1 glass jars filled with Lake Constance sediment and dechlorinated tap water. After $2 \mathrm{~d}$, plants were divided into two groups. Eight jars were covered with black nylon stockings (20\% denier yarn; $154 \pm 15 \mu \mathrm{mol} \mathrm{m} \mathrm{m}^{-2} \mathrm{~s}^{-1}$, mean \pm SD), and the others remained uncovered $\left(544 \pm 30 \mu \mathrm{mol} \mathrm{m} \mathrm{m}^{-2} \mathrm{~s}^{-1}\right)$. Water temperature varied between 18.4 and $20.1^{\circ} \mathrm{C}$. After $2 \mathrm{wk}$, plants from both treatments were used as food, and $P$. lucens as control ( $N=15$ per treatment).

To test whether chemicals present in E. nuttallii affected feeding behavior, growth, and/ or survival of the larvae, Acentria were fed in two different no-choice assays either with untreated, control-solvent, crude polar extract, or flavonoid fraction treated leaf squares $(N=14$ per treatment in both assays). Depending on consumption of the leaves, we prepared new leaf squares every 1-3 d. Together with new food, we also changed the inner filter. Over $20 \mathrm{~d}$, 
headcapsule width was measured four times. In addition, the feeding behavior of individual larvae and feeding damage on the leaves was assessed. In experiment IIIa, we only discriminated between damaged and undamaged leaf squares. In experiment IIIb, we distinguished five damage categories: no damage, low consumption corresponding to $1-33 \%$ of the leaf, medium (34-66\%) and high consumption (67-99\%), or whole leaf square consumed.

Statistical Analysis All analyses were conducted with the statistical package JMP IN 5.1 (SAS Institute Inc.), Statistica 6.0 (StatSoft, Inc., Tulsa) or with the software "R", version 2.3.0 (Ihaka and Gentleman, 1996). Nutrient concentrations, flavonoid content, and headcapsule widths were analyzed, whenever possible, by analysis of variance (ANOVA) followed by unequal $N$ HSD tests. This test is equivalent to the Tukey HSD test, but considers unequal sample sizes. Homogeneity of variances was tested by using Levene's test, and data were considered normally distributed when Kolmogorov-Smirnov tests resulted in $P>0.05$. When transformation failed to correct for heterogeneity of variances, we used Kruskal-Wallis $H$ tests. Individual growth of larvae in experiment IIIa was compared by $t$-test ( $E$. nuttallii vs solvent control). Mortality and feeding behavior of the larvae were analyzed by $\chi^{2}$ contingency tests or Fisher's exact test. In experiment IIIb, we determined the relative proportion of every consumption level for each larva. The relative proportion is calculated as the number of observations of the consumption level divided by the sum of all observations. Differences in feeding behavior of larvae $(N=14)$ in the five treatments were analyzed separately for each of the five consumption levels by using Kruskal-Wallis $H$ tests. If these revealed significant differences $(P<0.05)$ between groups, the data were compared by Nemenyi tests $(k=5$ treatments, $N=14$ replicates; difference in rank sums $>293.8$ for $\alpha=0.05$ ).

\section{Results}

Nutrient Content Carbon concentrations varied slightly between Elodea from the field (36.9 and $35.8 \%$ in sun-and-shade-exposed plants) and $P$. lucens (38.7\%, one-way ANOVA, $F_{2,13}=4.05, P=0.043$ ), yet pairwise differences were not significant (unequal $N$ HSD test, $P>0.05$ ) (Fig. 1). Nitrogen content in P. lucens was lower than in E. nuttallii collected in shaded areas (2.3 vs $3.3 \%$; unequal $N$ HSD, $P=0.031)$. Phosphorus content did not differ among treatments in experiment IIa (one-way ANOVA, $F_{2,13}=3.07, P=0.081$ ).

Elodea grown under high and low light in the light chamber had slightly lower carbon contents than P. lucens (37.6 and $36.2 \%$ vs $40.7 \%$; unequal $N$ HSD, $P=0.039$ and 0.002 , respectively). Nitrogen content ranged from 3.4 to $3.7 \%$ and did not vary among plants. Phosphorus concentrations were higher in P. lucens than in low and high light grown Elodea (0.49 vs 0.26 and $0.22 \%$; unequal $N$ HSD; $P=0.036$ and 0.006 , respectively).

Flavonoid Content Diglucuronides of luteolin, apigenin, and chrysoeriol were present in all Elodea samples but not in P. lucens (Fig. 2). In some, but not all samples of the latter, a compound with a similar absorption spectrum $\left(\lambda_{\max }\right.$ at 249,289 , and $\left.329 \mathrm{~nm}\right)$ but a longer retention time was present, indicating the presence of another flavonoid. Elodea from the field contained more apigenin- and chrysoeriol-7- $O$-diglucuronides than plants cultured in the light chamber (two-way ANOVA, $F_{1,28}=62.09$ for apigenin and 58.93 for chrysoeriol, $P<0.001)$, whereas the luteolin glucuronide did not differ $\left(F_{1,28}=3.37, P=0.077\right)$. In both experiments, flavonoid concentrations were independent of light regime $(P>0.7)$. 
Fig. 1 Nutrient content ( $\% \mathrm{dm})$ of fresh P. lucens and E. nuttallii from different light regimes used in growth assays with Acentria. In experiment a, E. nuttallii was collected in the field. In experiment $b$, it derived from a laboratory culture. Data represent means + SE $(N=2-10)$. Different letters indicate significant differences $P<0.05$
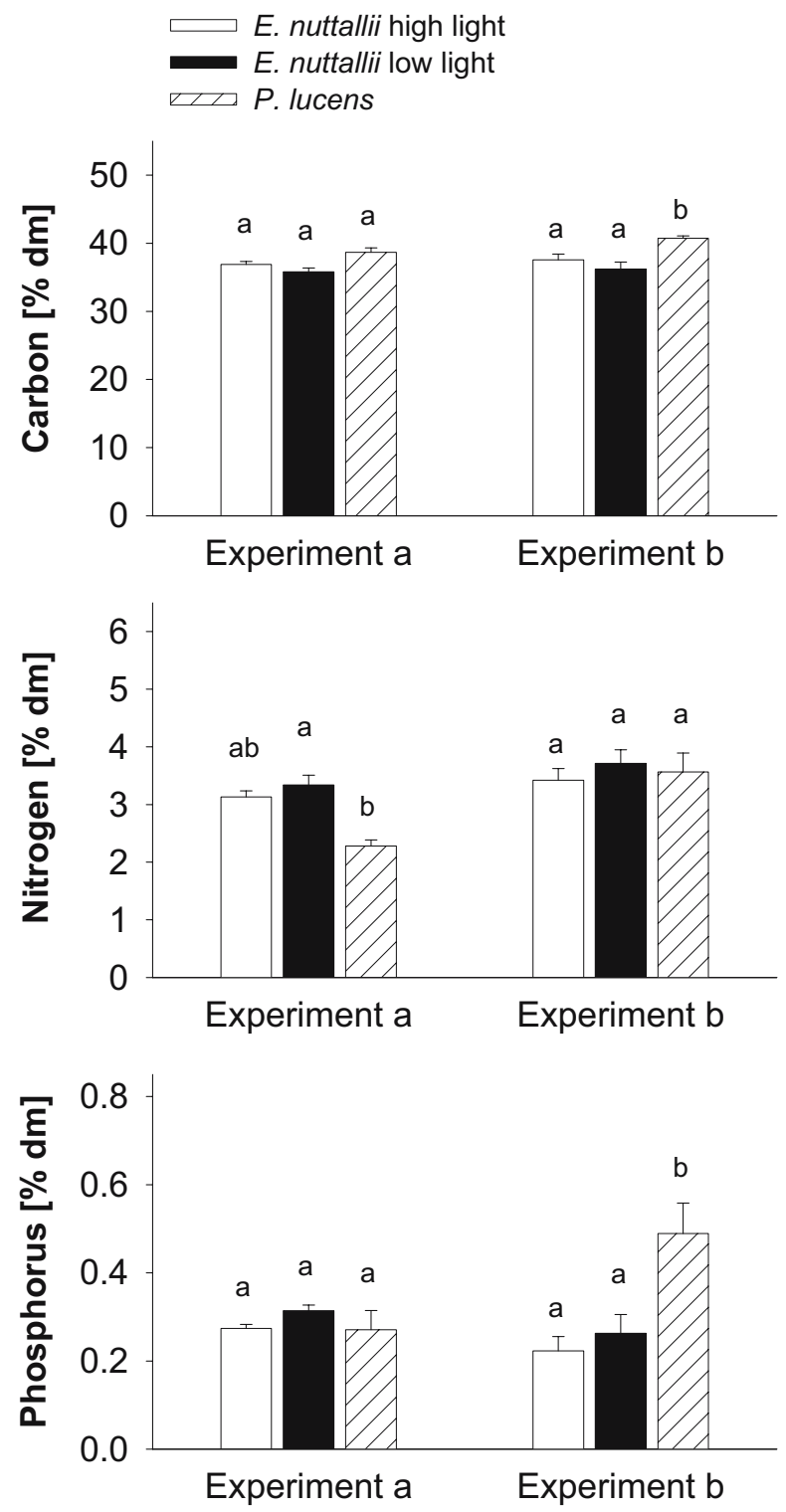

Performance of Neonate Larvae (Experiment I) Neonate larvae of Acentria experienced a high mortality $(65-100 \%)$ during the first weeks after hatching. Significantly more larvae died when fed only E. nuttallii compared to those fed first on $P$. perfoliatus for $5 \mathrm{wk}$ and then moved to $E$. nuttallii or those fed only P. perfoliatus (Table 1). Furthermore, larvae fed $E$. nuttallii for 7 or $5 \mathrm{wk}$ (EN and PF1) remained smaller than larvae fed most of the time (5 wk) or always on $P$. perfoliatus (PF2 and PF3; unequal $N$ HSD, $P<0.05$ each after two-way ANOVA, clutch I: treatment, $F_{2,59}=3.39, P=0.04$; clutch II: treatment, $F_{3,103}=8.67, P<0.001$; data not shown). 
Fig. 2 Content ( $\mu \mathrm{g} \mathrm{mg}{ }^{-1}$ plant $\mathrm{dm}$ ) of 7-O-diglucuronides of luteolin, apigenin, and chrysoeriol in E. nuttallii from different light regimes (high and low light) used in growth experiments with field collected plants (experiment a) and laboratory grown plants (experiment b). Data represent means + SE $(N=7-10)$. Different letters indicate significant differences $P<0.001$

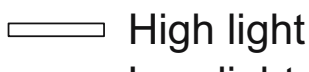

\section{Low light}
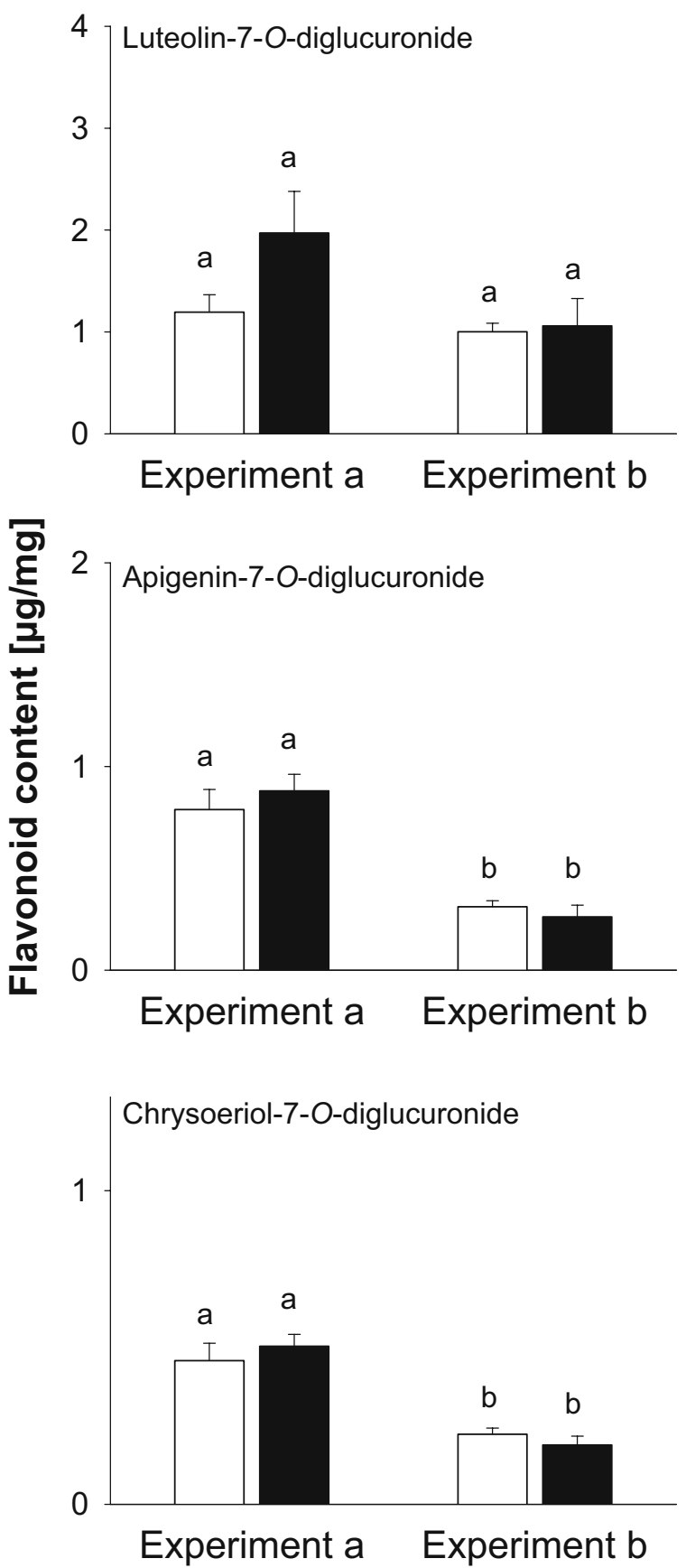
Mortality of Older Larvae When reared on fresh plants (experiments IIa and b), none of the larvae fed $P$. lucens died, whereas feeding on Elodea grown in high light led to increased mortality (46 and 53\%; $\chi^{2}$-test, $P=0.02$ and 0.004 , respectively; Fig. $3 \mathrm{a}$ and b). We observed high fatalities in the first experiment with supplemented leaves (experiment IIIa; Fig. 3c and d), which were mainly caused by escaping larvae. Of the initial 14 larvae, eight fled from the Elodea treatment and five from the controls. Four larvae died in the Elodea treatment, whereas all control larvae survived, resulting in a significantly increased mortality in the Elodea treatment $\left(\chi^{2}=7.337, P=0.007\right)$. To prevent escape of larvae in experiment IIIb, we sealed petri dishes with parafilm so that mortality was mainly based on larvae that died in the treatments. Only a few larvae escaped (four from the Elodea treatment and one from each of the flavonoid and flavonoid control treatments) due to leaks in the parafilm seal. Similar to experiment IIIa, mortality in the crude extract treatment was marginally increased compared to the other treatments $\left(\chi^{2}=9.333, P=0.053\right)$. Flavonoids caused no higher mortality compared to controls (Fig. 3d).

Growth on Elodea Under Different Light Regimes In experiment IIa, larvae fed P. lucens increased by $77 \%$ in headcapsule width, while those fed sun-exposed and shaded E. nuttallii increased by only 18-36\%, respectively (Fig. 4a). A two-way ANOVA showed significant food plant and time effects and an interaction of both (plant, $F_{2,163}=18.672, P<0.001$; time, $F_{4,163}=32.616, P<0.001$; plant $\times$ time, $\left.F_{8,163}=3.6, P<0.001\right)$.

Similar results were obtained in experiment IIb, where $E$. nuttallii was cultured at low or high light intensity in the laboratory. Both low and high light grown E. nuttallii suppressed Acentria growth compared to P. lucens (Fig. 4b). Here, larvae fed low or high light $E$. nuttallii grew by only $7-15 \%$ (both fourth/fifth instar), respectively, and were not significantly different (unequal $N$ HSD, $P>0.05$ ). In contrast, larvae reared on Potamogeton grew by $39 \%$ and were larger than those in both Elodea treatments (fifth/sixth instar; $P \leq 0.029$ ). A two-way ANOVA comparing growth after day 12 exhibited significant food plant and time effects but no interaction effect (plant, $F_{2,106}=37.90, P<0.001$; time, $F_{2,106}=5.05, P<0.001$; food $\times$ time, $\left.F_{4,106}=0.32, P=0.867\right)$.

Growth of Acentria on Elodea-Supplemented Leaves We compared growth of Acentria reared on untreated leaf squares with the growth of larvae fed with leaves incubated in crude polar extract. Starting with day 12, larvae reared on Elodea-extract supplemented leaves were smaller than larvae that received control leaf squares (Fig. 4c). Headcapsule width at the beginning of the experiment was $502 \pm 54$ and $502 \pm 51 \mu \mathrm{m}$ (mean $\pm \mathrm{SE}, N=14$ each) for treatment and control, respectively. At day 20, larvae reared on untreated leaf squares had reached a mean size of $676 \pm 85 \mu \mathrm{m}(N=9)$, whereas the two remaining larvae fed Elodea supplemented leaves had only 557 and $574 \mu \mathrm{m}(N=2)$. Although these values are outside the $95 \%$ confidence interval of the control mean (i.e., 607-745 $\mu \mathrm{m}$ ), repeated measures ANOVA (rmANOVA) did not detect any differences between the two groups. As this might be due to the high mortality in the Elodea treatment, we compared the individual growth of surviving larvae in the treatments. Headcapsule width of control larvae increased by $176 \pm 22 \mu \mathrm{m}($ mean $\pm \mathrm{SE})$, significantly more than that in the Elodea treatment $(46 \pm 21 \mu \mathrm{m}$; $P=0.028, t$-test).

Enrichment of P. lucens with E. nuttallii Extract After incubation in aqueous E. nuttallii extract, $P$. lucens leaf squares contained $0.35 \pm 0.05 \% \mathrm{dm}($ mean $\pm \mathrm{SD}, N=3)$ luteolin-7-Odiglucuronide and $0.05 \pm 0.004 \% \mathrm{dm}$ of the other flavonoids (apigenin and chrysoeriol-7-Odiglucuronides). When these leaf squares were placed on moist filter paper, most of the 


\section{Fresh plants}

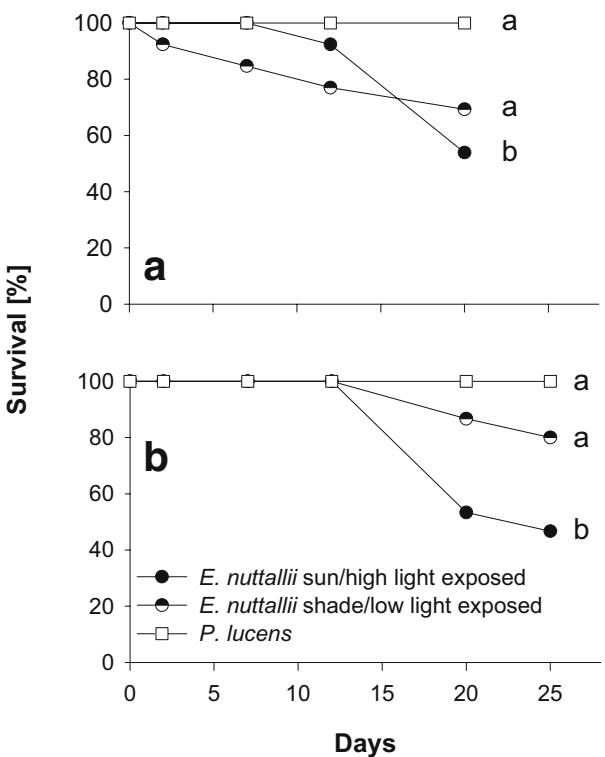

\section{Leaf disks}
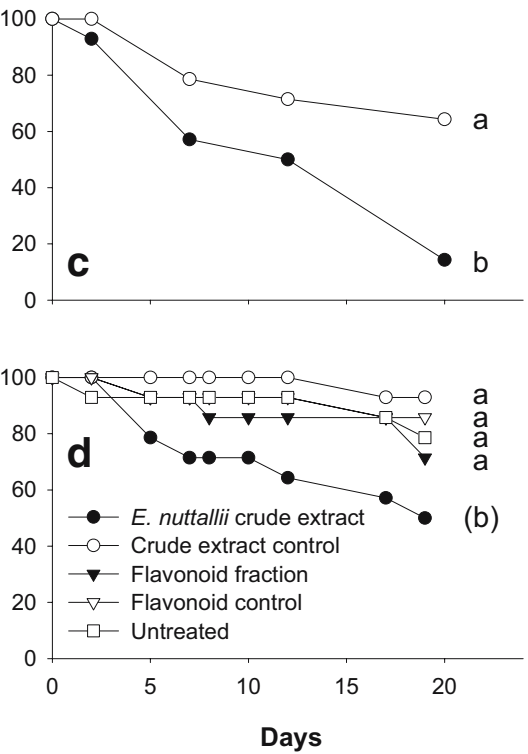

Fig. 3 Survival of Acentria on fresh plants (left panel) and supplemented P. lucens leaf disks (right panel) in four independent experiments (initial $N=13-15$ each). a field collected plants, b laboratory grown plants, c leaf squares supplemented with crude polar extract, d leaf squares supplemented with extract fractions as food source. Letters on the right indicate significant $(P<0.05)$ groupings among treatments based on $\chi^{2}$ analyses. Letters in parentheses indicate marginal differences $(P<0.1)$

\section{Fresh plants}

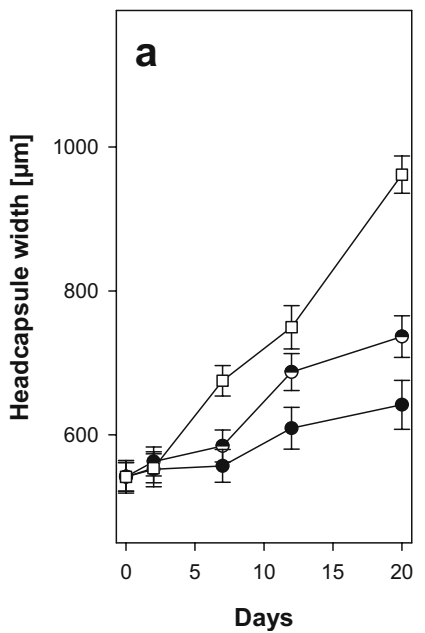

\section{b}

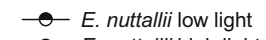

$\rightarrow-$ E. nuttallii high light

$\rightarrow \square$ P. lucens

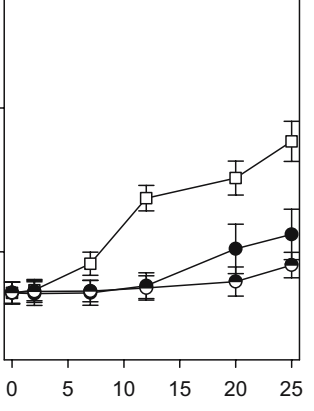

Days
Leaf disks

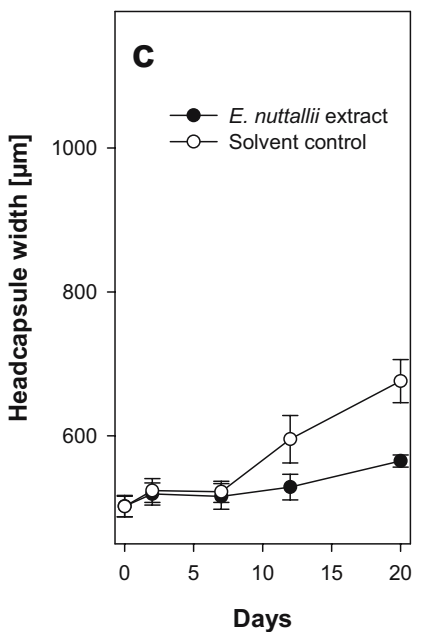

Fig. 4 Growth, measured as headcapsule width $(\mu \mathrm{m})$ of Acentria larvae fed fresh plants from the field (a) and from the laboratory (b) or supplemented P. lucens leaf disks (c). $N=15$ (a), 13 (b), and 14 (c) per treatment at beginning. Data represent means $\pm \mathrm{SE}$ 
flavonoids directly diffused into the filter. Only $0.09 \pm 0.03 \%$ of luteolin and $0.01 \pm 0.002 \%$ of apigenin/chrysoeriol were found at this time in the leaves, indicating that flavonoids were adsorbed at the surface of $P$. lucens, but were not incorporated into the plant tissue. Amounts detected in the filter paper were 0.8-2.4 and 1.5-2.8 times compared to total leaf squares (luteolin and apigenin/chrysoeriol, respectively). After $24 \mathrm{hr}$, leaves still contained $0.01 \pm 0.007 \%$ of the luteolin-diglucuronide, and $0.002 \%$ of apigenin/chrysoeriol. At the same time, filter disks had flavonoid contents up to 8.7 (luteolin) and 12.3 times (apigenin/ chrysoeriol) higher than the total respective supplemented leaves.

Feeding Behavior of Acentria Larvae fed significantly more often on P. lucens soaked in control solvent than on extract treated leaf disks (experiment IIIa, Fisher's exact test, $P<0.001$ ). In experiment IIIb, we tested whether flavonoids present in E. nuttallii influence feeding patterns (Fig. 5). Larvae in this assay exhibited normal feeding behavior that was not different from other assays, but headcapsule widths did not increase at all, even in controls. We observed that larvae were growing, indicated by a visible increase in larval body size. We distinguished the amount of leaf consumed to gain information on larval food uptake. It was striking that larvae did not eat much in all treatments during the first 2 days. Thus, groups did not differ from each other on day 2 ( $H$-test, $P=0.458)$. After this period, consumption increased in the controls, to a lesser extent in the flavonoid treatment, but not in the crude extract treatment, where until day 10, only two of the offered leaf pieces were damaged (data not shown). In each treatment, except in the crude extract control, some larvae did not eat at all. More larvae showed no consumption in the crude extract and flavonoid treatment $(N=5$ each) than in untreated leaves $(N=2)$ and in the flavonoid control $(N=1)$. We observed all levels of consumption in every group, but most larvae reared on leaves impregnated with crude polar extract or flavonoids did not feed $(86.6 \pm 3.7 \%$ and $71.1 \pm 7.5 \%$, mean \pm SE, respectively), while total avoidance was less frequent in all three control groups $(39.4,32.5$, and $32.4 \%$ of untreated, extract, and flavonoid controls, respectively; Nemenyi test $P<0.05$, following $H$ test, $H=30.865, P<0.001)$. In control treatments, larvae consumed significantly more entire leaf pieces (39.6, 41.7, and 49.4\%; Nemenyi test $P<0.05$, following $H$ test, $H=36.919, P<0.001$ ). A difference in the high consumption level was only visible for the crude extract fed larvae. The proportions of low and moderate consumption ranged between 1.4 and $8.6 \%$ and did not differ between groups.

\section{Discussion}

Acentria larvae perform better on native pondweed than on the invasive E. nuttallii. When reared on suitable food plants, Acentria usually has six larval instars until pupation (Gross et al. 2002). Larvae fed Potamogeton reached this instar, while those fed E. nuttallii had headcapsule widths equivalent to the fourth or fifth instar within the same time span. This indicates that larval development on Elodea is delayed. Even if surviving larvae would enter the pupal stage, the prolonged larval development might lead to lower pupal weight, reduced female fecundity, or greater time of exposure to enemies (Price et al. 1980; Haukioja and Neuvonen 1985; Tikkanen et al. 2000).

The impact of E. nuttallii on neonate larvae apparently differs from that on older instars after hibernation, which we used in our further experiments. Although there might be exceptions, first instars generally experience higher mortality rates than later instars (Zalucki et al. 2002). Our results with newly hatched larvae show a significant increase in 
Fig. 5 Proportional contribution $[\times 100 \%]$ of different consumption levels among treatments during experiment IIIb. Given are means + SE $(N=14$ per treatment). Different letters indicate significant groupings among treatments ( $H$ test followed by Nemenyi test, $P<0.05)$. Levels of feeding damage correspond to $0 \%$ (no), $1-$ 33\% (low), 34-66\% (moderate), 67-99\% (high), and 100\% (all)

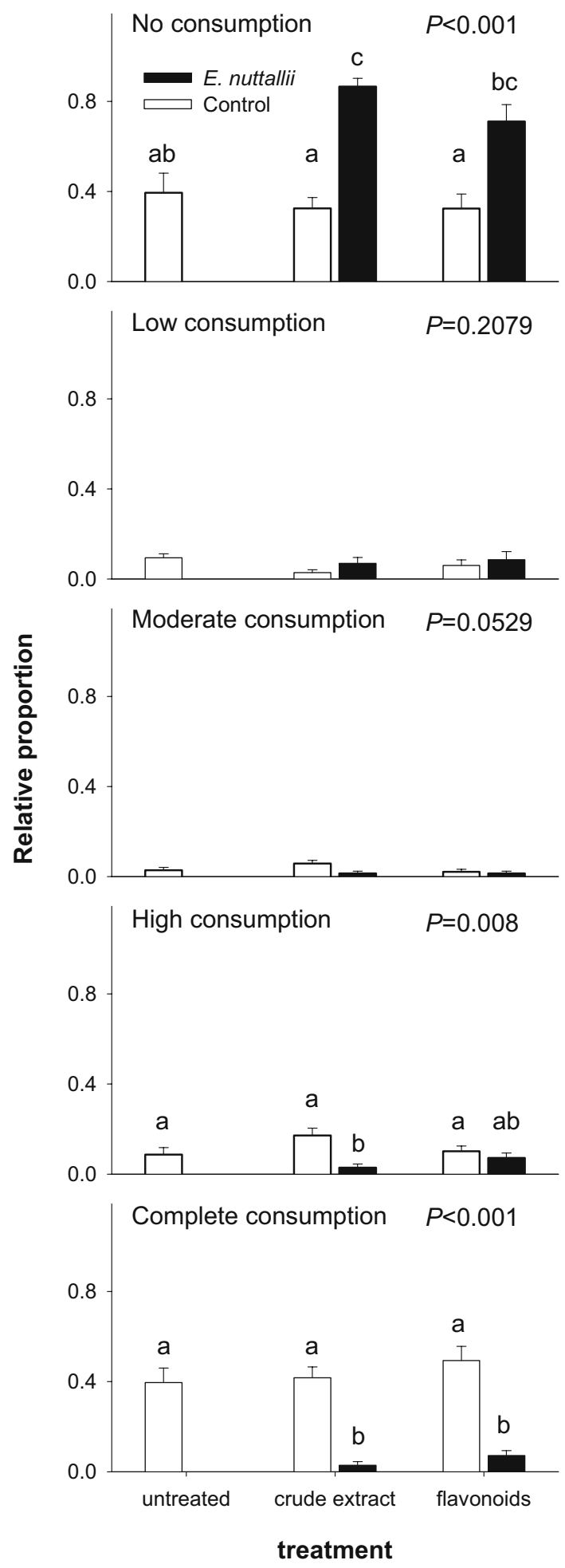


mortality of early instar Acentria when fed E. nuttallii, ranging between 90 and $100 \%$. In a comparable experiment, E. canadensis increased mortality of early instars but only to $50 \%$ (Gross et al. 2001). This suggests a more deleterious impact of E. nuttallii on the fitness of Acentria than E. canadensis. A direct comparison of both species in one experiment is needed for final proof.

Structural defenses are most likely not a reason for the poor performance of Acentria larvae on E. nuttallii, as leaves consist of only two cell layers, and plants were consumed by larvae in our assays. Also, nutritive value did not explain the reduced growth or survivorship of larvae. The average nitrogen content ranged from 3.1 to $3.7 \%$ in $E$. nuttallii, comparable to other studies (Newman 1991; Kornijow et al. 1995) and within the range of 1.2 to $4.8 \%$ for various submersed angiosperms (Boyd 1968; Jewell 1971; Muztar et al. 1978; Choi et al. 2002).

Cronin and Lodge (2003) measured lower nitrogen levels in freshwater plants grown under high light conditions, but palatability did not differ between treatments. In $M$. spicatum, high light increased nitrogen content (Gross 2003). In our experiments, light had no significant effect on nitrogen content in Elodea, and its concentrations did not differ from that in Potamogeton. Kornijow et al. (1995) also found low C:N ratios in E. nuttallii, and they considered factors other than nutritional value important for herbivores. Also, food plants were never phosphorus limited (Gerloff and Krombholz 1966). Due to the negligible differences in nutrient content in food plants, we consider neither nitrogen nor phosphorus responsible for the bad larval performance.

Our results indicate that allelochemicals in E. nuttallii deter feeding by Acentria and might inhibit growth of larvae. Crude polar extract and a fraction containing the major three flavonoids from Elodea deterred Acentria from feeding on P. lucens leaves, while untreated or solvent control leaves of $P$. lucens were often completely consumed (Fig. 5). Not many studies have yet investigated chemical defenses in submerged freshwater angiosperms. Many studies have focused on marine macroalgae (Hay 1996; Paul et al. 2006) and emergent or floating-leaved freshwater angiosperms (Bolser and Hay 1998; Dorn et al. 2001; Kubanek et al. 2001; Prusak et al. 2005). These studies often used omnivorous crustaceans as grazers, against which extracts of submersed species have turned out to be inactive (Bolser et al. 1998; Prusak et al. 2005). In contrast, other authors have suggested chemical defenses in submerged freshwater macrophytes against planktivorous Daphnia, lepidoptera, and gastropod herbivores based on observed effects and correlations between secondary plant metabolites and feeding activity or changes in behavior (Pennak 1973; Burks et al. 2000; Choi et al. 2002; Cohen et al. 2002; Elger and Lemoine 2005). None of these studies tested isolated chemicals.

The lack of studies establishing evidence for chemical defenses in (submerged) freshwater macrophytes results from methodical problems. Omnivores or shredder herbivores accept various artificial diets (Lodge 1991; Newman et al. 1996; Bolser et al. 1998). The specialized feeding habits of invertebrates challenges the design of suitable artificial diets (Hay et al. 1998). Acentria feeds on several species in different freshwater plant families and can thus be regarded as a generalist (Buckingham and Ross 1981). Nevertheless, it consumes exclusively fresh tissue from submerged angiosperms and rejects decaying material or common artificial diets (Choi et al. 2002; D.E. and E.M.G., personal observations).

Acentria larvae did not feed on boiled plant material or other artificial diets (data not shown), and only extract coated fresh leaves could be used in feeding assays. A similar design, in which Salix leaves were coated with extracts of several floating-leaved freshwater macrophytes, was used previously in feeding assays with the semiaquatic 
lepidopteran Munroessa gyralis (Dorn et al. 2001). We tested whether coating of P. lucens leaves with $E$. nuttallii extract or fractions would decrease their palatability. The coating of $P$. lucens leaves with $E$. nuttallii extract was not simple. The leaves are thin and do not have a substantial cuticle, which makes them sensitive to organic solvents or wilting. Moist conditions promoted the diffusion of the amphiphilic active compounds in our extracts of $E$. nuttallii. It was necessary to minimize the leaching of extracts into the surrounding medium to make the exposure to active compounds as realistic as possible. The amount of flavonoids enriched in $P$. lucens equaled that of concentrations found in field samples of $E$. nuttallii $(0.02-1.2 \%$ of plant $\mathrm{dm}$ for luteolin-7-O-diglucuronide, calculated from values in Fig. 2 and those given in Mues 1983), but flavonoids leached very quickly from the leaves. The inner filter paper prevented the diffusion of the compounds to the outer filter paper, where larvae in Elodea treatments spent most of their time. Thus, larvae came in contact with E. nuttallii allelochemicals only when they entered the inner filter disk for feeding. Although our method can be further improved, we assume that during feeding on or mining into stems of E. nuttallii, Acentria would, to some extent, also be exposed to secondary compounds leaching from wounded cells.

E. nuttallii crude polar extracts applied to P. lucens leaves had the most deleterious effect on Acentria. This treatment reduced survival, growth, and feeding (Figs. 3, 4, and 5). The observed mortality with crude polar extract equaled that of live E. nuttallii plants (Fig. 3). The increase in headcapsule width of larvae grown with E. nuttallii extract was less than $50 \%$ of that of $P$. lucens fed larvae and corresponds to the values observed in the assays with fresh plants (Fig. 4). This corroborates our hypothesis that the negative impact of $E$. nuttallii on Acentria is mainly due to chemical defenses. Our results indicate that flavonoids can act as feeding deterrents in E. nuttallii, but they do not affect survival (Fig. 3). Corresponding to our results, Beninger and Abou-Zaid (1997) observed a high mortality of Lymantria dispar when fed crude extract of jack pine, but not when fed jack pine flavonoids alone. Elliger et al. (1980) found several flavonoids that inhibited growth of Heliothis zea, but none of them affected survival. Thus, there must be additional unknown, metabolites present in E. nuttallii crude polar extracts that exhibit toxicity or act at least additively or synergistically to flavonoids. Our approach opens the possibility of identifying additional relevant signals in a bioassay guided structure elucidation.

The deleterious effect of E. nuttallii extracts on Acentria confirms earlier suggestions that Elodea spp. might be defended against herbivores (Newman 1991; Kornijow et al. 1995). The natural concentrations of the luteolin-derivative in E. nuttallii $(0.02-1.2 \%$ of plant dry mass, see above) and the other two flavonoids (at least $0.014 \%$ for chrysoeriol glucuronide and $0.02 \%$ for apigenin glucuronide; Mues 1983) are comparable to the content of structurally related allelochemicals found in other plant species (Beninger and Abou-Zaid 1997). Even though the enrichment of P. lucens with E. nuttallii extracts yielded concentrations only at the lower range found in field $E$. nuttallii, our observed effects suggest that chemical defense should be relevant under natural conditions. All three flavonoids are also present in E. canadensis (Mues 1983; Erhard et al. unpublished results.), which is similarly avoided by the moth (Gross et al. 2001), but they do not occur in $P$. lucens or M. spicatum (data not shown), which suffer from severe feeding damage by Acentria in the field (Gross et al. 2002). Both the effect of Elodea secondary allelochemicals as feeding deterrents and inhibitors of survival and growth might reduce the risk of herbivory on Elodea.

Our results show that potential allelochemicals are present in Elodea leaves as well as coated Potamogeton leaves in low but ecologically relevant concentrations, comparable to concentrations effective in terrestrial systems (Beninger and Abou-Zaid 1997). We thus 
assume that the chemical defense in E. nuttallii is a powerful trait to protect plants against herbivores and might further strengthen the invasiveness of this species.

Acknowledgments We acknowledge the help of Julia Hoffmann, Nadine Womann, and Manuela Mayer during the feeding assays. Vera Bauke is acknowledged for help during the extraction and purification of flavonoids. Heather Fyson improved the English, and two anonymous reviewers made valuable comments on the manuscript. This study was supported by the German Science Foundation (DFG, project A2 in SFB454 to EMG) and the University of Konstanz (AFF).

\section{References}

BENINGER, C. W. and ABOU-ZAID, M. M. 1997. Flavonol glycosides from four pine species that inhibit early instar gypsy moth (Lepidoptera: Lymantriidae) development. Biochem. Syst. Ecol. 25:505-512.

BERG, K. 1941. Contributions to the biology of the aquatic moth Acentropus niveus (Oliv.). Vidensk. Medd. Dansk Naturh. Foren. 105:59-139.

BOLSER, R. C. and HAY, M. E. 1998. A field test of inducible resistance to specialist and generalist herbivores using the water lily Nuphar luteum. Oecologia 116:143-153.

Bolser, R. C., Hay, M. E., Lindquist, N., Fenical, W., and Wilson, D. 1998. Chemical defenses of freshwater macrophytes against crayfish herbivory. J. Chem. Ecol. 24:1639-1658.

BoyD, C. E. 1968. Fresh-water plants: a potential source of protein. Econ. Bot. 22:359-368.

Buckingham, G. R. and Ross, B. M. 1981. Notes on the biology and host specificity of Acentria nivea (=Acentropus niveus). J. Aquat. Plant Manage. 19:32-36.

Burks, R. L., JEPPESEN, E., and LodGe, D. M. 2000. Macrophyte and fish chemicals suppress Daphnia growth and alter life-history traits. Oikos 88:139-147.

Calderon, J. S., Cespedes, C. L., Rosas, R., Gomez-Garibay, F., Salazar, J. R., Lina, L., Aranda, E., and KUBO, I. 2001. Acetylcholinesterase and insect growth inhibitory activities of Gutierrezia microcephala on fall armyworm Spodoptera frugiperda J. E. Smith. Z. Naturforsch. 56c:382-394.

CHOI, C., BAREISS, C., WALENCIAK, O., and Gross, E. M. 2002. Impact of polyphenols on growth of the aquatic herbivore Acentria ephemerella. J. Chem. Ecol. 28:2245-2256.

Cohen, M. F., Meziane, T., Tsuchiya, M., and Yamasaki, H. 2002. Feeding deterrence of Azolla in relation to deoxyanthocyanin and fatty acid composition. Aquat. Bot. 74:181-187.

Cook, C. D. K. and URmi-KÖNIG, K. 1985. A revision of the genus Elodea (Hydrocharitaceae). Aquat. Bot. 21:111-156.

Cronin, G. and Lodge, D. M. 2003. Effects of light and nutrient availability on the growth, allocation, carbon/nitrogen balance, phenolic chemistry, and resistance to herbivory of two freshwater macrophytes. Oecologia 137:32-41.

CruZ-RIVERA, E. and HAY, M. E. 2003. Prey nutritional quality interacts with chemical defenses to affect consumer feeding and fitness. Ecol. Monogr. 73:483-506.

Dorn, N. J., Cronin, G., and Lodge, D. M. 2001. Feeding preferences and performance of an aquatic lepidopteran on macrophytes: plant hosts as food and habitat. Oecologia 128:406-415.

Elger, A. and LEMoINE, D. 2005. Determinants of macrophyte palatability to the pond snail Lymnaea stagnalis. Freshw. Biol. 50:86-95.

Elliger, C. A., Chan, B. C., and Waiss Jr., A. C. 1980. Flavonoids as larval growth inhibitors-structural factors governing toxicity. Naturwissenschaften 67:358-360.

ERHARD, D. and GROSS, E. M. 2005. Do environmental factors influence composition of potential allelochemicals in the submersed freshwater macrophyte Elodea nuttallii (Hydrocharitaceae)? Verh. Internat. Verein. Limnol. 29:287-291.

ERHARD, D. and GROSS, E. M. 2006. Allelopathic activity of Elodea canadensis and Elodea nuttallii against epiphytes and phytoplankton. Aquat. Bot. 85:203-211.

Gerloff, G. C. and Krombholz, P. H. 1966. Tissue analysis as a measure of nutrient availability for the growth of angiosperm aquatic plants. Limnol. Oceanogr. 11:529-537.

Gross, E. M. 2003. Differential response of tellimagrandin II and total bioactive hydrolysable tannins in an aquatic angiosperm to changes in light and nitrogen. Oikos 103:497-504.

Gross, E. M., FeldBaum, C., and CHOI, C. 2002. High abundance of herbivorous Lepidoptera larvae (Acentria ephemerella DENIS \& SCHIFFERMÜLLER) on submersed macrophytes in Lake Constance (Germany). Arch. Hydrobiol. 155:1-21. 
Gross, E. M., Johnson, R. L., and Hairston Jr., N. G. 2001. Experimental evidence for changes in submersed macrophyte species composition caused by the herbivore Acentria ephemerella (Lepidoptera). Oecologia 127:105-114.

Haukioja, E. and Neuvonen, S. 1985. The relationship between size and reproductive potential in male and female Epirrita autumnata (Lep., Geometridae). Ecol. Entomol. 10:267-270.

HAY, M. E. 1996. Marine chemical ecology: what's known and what's next? J. Exp. Mar. Biol. Ecol. 200:103-134.

HaY, M. E., KAPPEL, Q. E., and FenICAL, W. 1994. Synergisms in plant defenses against herbivores: interactions of chemistry, calcification, and plant quality. Ecology 75:1714-1726.

Hay, M. E., Stachowicz, J. J., Cruz-Rivera, E., Bullard, S., Deal, M. S., and Lindquist, N. 1998. Bioassays with marine and freshwater macroorganisms, pp. 39-141, in K. F. Haynes and J. G. Millar (eds.). Methods in Chemical Ecology. Kluwer Academic Publishers, Norwell, Massachusetts.

IHAKA, R. and Gentleman, R. 1996. R: A language for data analysis and graphics. J. Comput. Graph. Stat. 5:299-314.

JEWELL, W. J. 1971. Aquatic weed decay: dissolved oxygen utilization and nitrogen and phosphorus regeneration. J. Water Pollut. Control Fed. 43:1457-1467.

KorniJOW, R., GULATI, R. D., and OZIMEK, T. 1995. Food preference of freshwater invertebrates: comparing fresh and decomposed angiosperm and a filamentous alga. Freshw. Biol. 33:205-212.

KubaneK, J., Hay, M. E., Brown, P. J., Lindquist, N., and Fenical, W. 2001. Lignoid chemical defenses in the freshwater macrophyte Saururus cernuus. Chemoecology 11:1-8.

LodGe, D. M. 1991. Herbivory on freshwater macrophytes. Aquat. Bot. 41:195-224.

Mues, R. 1983. Species specific flavone glucuronides in Elodea species. Biochem. Syst. Ecol. 11:261-265.

Muztar, A. J., Slinger, S. J., and Burton, J. H. 1978. Chemical composition of aquatic macrophytes. I. Investigation of organic constituents and nutritional potential. Can. J. Plant Sci. 58:829-841.

NEWMAN, R. M. 1991. Herbivory and detritivory on freshwater macrophytes by invertebrates: a review. $J$. North Am. Benthol. Soc. 10:89-114.

Newman, R. M., Kerfoot, W. C., and Hanscom III, Z. 1996. Watercress allelochemical defends highnitrogen foliage against consumption: effects on freshwater invertebrate herbivores. Ecology 77:23122323.

Ostrofsky, M. L. and Zettler, E. R. 1986. Chemical defences in aquatic plants. J. Ecol. 74:279-287.

Paul, V. J., Puglisi, M. P., and Ritson-williams, R. 2006. Marine chemical ecology. Nat. Prod. Rep. 23:153-180.

PENNAK, R. W. 1973. Some evidence for aquatic macrophytes as repellents for a limnetic species of Daphnia. Int. Rev. Gesamten. Hydrobiol. 58:569-576.

Perkins, M. C., Woods, H. A., Harrison, J. F., and Elser, J. J. 2004. Dietary phosphorus affects the growth of larval Manduca sexta. Arch. Insect Biochem. Physiol. 55:153-168.

Price, P. W., Bouton, C. E., Gross, P., McPheron, B. A., Thompson, J. N., and Weis, A. E. 1980. Interactions among three trophic levels: influence of plants on interactions between insect herbivores and natural enemies. Annu. Rev. Ecol. Syst. 11:41-65.

Prusak, A. C., O’Neal, J., and KubaneK, J. 2005. Prevalence of chemical defenses among freshwater plants. J. Chem. Ecol. 31:1145-1160.

Simmonds, M. S. J. and StEVENSON, P. C. 2001. Effects of isoflavonoids from Cicer on larvae of Heliocoverpa armigera. J. Chem. Ecol. 27:965-977.

Simpson, D. A. 1990. Displacement of Elodea canadensis Michx by Elodea nuttallii (Planch.) H. St John in the British Isles. Watsonia 18:173-177.

TikkAnen, O.-P., Niemelä, P., and KerÄNEN, J. 2000. Growth and development of a generalist insect herbivore, Operophtera brumata, on original and alternative host plants. Oecologia 122:529-536.

VAN DONK, E. and OTTE, A. 1996. Effects of grazing by fish and waterfowl on the biomass and species composition of submerged macrophytes. Hydrobiologia 340:285-290.

WALENCIAK, O., ZWISLER, W., and GROSS, E. M. 2002. Influence of Myriophyllum spicatum-derived tannins on gut microbiota of its herbivore Acentria ephemerella. J. Chem. Ecol. 28:2045-2056.

White, T. C. R. 1993. The inadequate environment. Nitrogen and the abundance of animals. SpringerVerlag.

Zalucki, M. P., Clarke, A. R., and Malcolm, S. B. 2002. Ecology and behavior of first instar larval Lepidoptera. Annu. Rev. Entomol. 47:361-393. 